\title{
Effect of flaxseed and corn oils on acute myocardial infarction in high fat diet fed rat
}

\author{
Nehal H Abdel-Halim ${ }^{1}$, Mohammad Ghalwash1, Mohammad MH Sarhan1and Mohammad ZA Borae1
}

${ }^{1} 1$ Department of Medical Physiology,

Faculty of Medicine, Mansoura University,

Egypt

\section{Background}

Dyslipidemia is one of the major risk factors for ischemic heart diseases. Vegetable oils as flaxseed and corn oils draw the attention because they owe many health benefits as antioxidant and anti-inflammatory. Objectives: This work aimed to study the possible role of flaxseed and corn oils in prevention or attenuation of acute myocardial infarction in male rats fed a high fat diet. Methods: 64 adult male rats were divided into 4 groups: ${ }^{(1)}$ control group standard diet fed rats, (2) high fat fed group (3) high fat diet and supplemented with flaxseed oil and (4) high fat diet and supplemented with corn oil group. After 8 weeks myocardial infarction was induced by isoprenaline injection for 2 consecutive days. ECG, serum lipid profile and serum CK-MB were assessed. Results: Flaxseed oil supplementation produce significant increase in QRS amplitude, shortening of QTc interval and less ST elevation. Flaxseed oil improved the lipid profile and decreased the serum level of CK-MB. Whereas corn oil supplementation showed, a significant decrease in ST segment elevation but insignificant change in QRS amplitude, and QTC interval. Corn oil significantly decrease CK-MB but less than flaxseed oil. Conclusion: Flaxseed and corn oils exhibit cardioprotective effects in attenuation of acute myocardial infarction in rats fed a high fat diet. Flaxseed oil has more cardioprotective effects may be attributed to its higher content of omega 3 fatty acids.

Keywords: flaxseed oil, corn oil, myocardial infarction, ECG.

\section{Introduction}

Cardiovascular diseases are considered the major cause of premature death in both developed and developing countries (Yokoyama, 2004). Dyslipidemia is one of the major risk factors for ischemic heart diseases. Myocardial infarction occurs due to sudden deprivation of circulating blood, hence limited oxygen supply. The incidence of acute myocardial infarction (AMI) is high, and it is the leading cause of death in the elderly (Gaby, 2010). Abnormal lipid metabolism is a main cause of dyslipidemia, which is a major risk factor for cardiovascular diseases, obesity, cholestasis and overall mortality (Garg \& Simha, 2007).

Vegetable oils have been used as functional food and for medicinal purposes for hyperlipidemia. Also, they may be useful adjuncts to reduce alterations in liver metabolism and the risk of cardiovascular disease. There are many studies demonstrated that ingestion of polyunsaturated fatty acids (PUFA) present in vegetable oils, is inversely proportional to the incidence of cardiovascular disease by reducing plasma triglyceride levels and cholesterol (Barcelo-Coblijn \& Murphy, 2009; Tzang et al., 2009). Omega 3 (PUFAs) are basically found in fish, particularly in anchovies, tuna and salmon. Flaxseed is considered an important source of PUFA, which is obtained from Linum usitatissimum plants (Linaceae family), cropped mainly in China, Argentina, Brazil, India, Canada and Turkey (Sammour, 1999). 
Flaxseed oil contains both omega 3 and omega 6 fatty acids, both of them are needed for health. Flaxseed oil consists of $55 \%$ alpha-linolenic acid (ALA) (Prasad, 2000), then it is converted inside the body into docosahexaenoic acid (DHA) and eicosapentaenoic acid (EPA) resembling the omega-3 fatty acids found in fish oil (Mantzioris et al., 1994). So flaxseed oil might have the same benefits as fish oil. Omega 3 fatty acids found in fish oil, have been shown to decrease inflammation and help to prevent many chronic diseases, such as arthritis and heart disease (Calder, 2004; Calder \& Yaqoob, 2009). Several studies have been investigating whether flaxseed oil is useful for the same conditions.

Corn oil constitutes a good source of essential fatty acids and their nutritional properties are excellent. Corn oil has high content of linoleic acid fatty acid. Linoleic acid is necessary for the integrity of the cell membranes, skin, the immune system, and for synthesis of eicosanoids. Eicosanoids are necessary for cardiovascular, renal, reproductive and gastrointestinal functions (Milin et al., 2001). Many fatty acids are found in corn oil as palmitic acid, oleic acid, stearic acid, linoleic acid and linolenic acid (Si et al., 2014). Corn oil contains 59\% polyunsaturated omega 6 (linoleic acid), 27\% monounsaturated (oleic acid), 13\% saturated fatty acids and $1 \%$ omega 3 (linolenic acid). Corn oil is rich of omega 6, phytosterols and tocopherols (Si et al., 2014). It is essential to get a good balance of omega 3 and omega 6 fatty acids in the diet (Calder, 2003). Omega 3 fatty acids tend to reduce inflammation; on the other side many omega 6 fatty acids tend to increase the inflammation. We should eat a healthy diet that consists of roughly $2-4$ times fewer omega- 6 fatty acids than omega-3 fatty acids (Burghardt et al., 2010).

The aim of this work is to study the possible role of flaxseed and corn oils in prevention or attenuation of experimental induced acute myocardial in- farction in male adult albino rats fed a high fat diet.

\section{Material and Methods}

\section{Materials:}

Flaxseed oil was purchased form (Sigma-Aldrich Co. Egypt) and stored in dark containers $(500 \mathrm{ml})$, and kept away from light (Nykter et al., 2006). Corn oil was purchased from (Beta Co. Egypt) in a container composed of $1000 \mathrm{ml}$. Isoprenaline was purchased from Sigma - Aldrich Company ( , in the form of poly bottle containing 5 gram of pure white powder of the active ingredient.

\section{Experimental Animals:}

The present study was carried out on 64 adult male rats ( 8 weeks age) weighed $150-250 \mathrm{~g}$. They were bred and housed at room temperature. They had free access to tap water and were fed a standard laboratory chow. All protocols in this study were approved by Mansoura Faculty of Medicine research ethics committee, Institute Research Board (IRB) code number (MS/552).

\section{Experimental design:}

In the present study, rats were divided randomly into 4 groups (16 rats in each):

Group (I): rats fed standard diet (carbohydrate $63.2 \mathrm{~g} / 100 \mathrm{gm}$, protein $22 \mathrm{~g} / 100 \mathrm{gm}$, fat $9.6 \mathrm{~g} /$ 100 gm) (Rasmy, 2007).

Group (II): rats fed a high fat diet (HFD) (carbohydrate $41 \mathrm{~g} / 100 \mathrm{gm}$, protein $20.6 \mathrm{~g} / 100 \mathrm{gm}$, fat $33 \mathrm{~g} / 100 \mathrm{gm}$ ) (Rasmy, 2007).

Group (III): rats fed a high fat diet and supplemented with flaxseed oil by oral gavage in a dose of $0.4 \mathrm{~g} /$ day per rat (Dupasquier et al., 2007).

Group (IV): rats fed a high fat diet and supplemented with corn oil by oral gavage in a dose of $0.4 \mathrm{~g} /$ day per rat (Dauqan et al., 2011).

After 8 weeks rats in each group were divided into 2 subgroups (each contains 8 rats) (Hussein et al., 2016):

Subgroup (a): non infarct group, in which rats 
were injected with $0.5 \mathrm{ml}$ saline subcutaneously after 12 hours fasting for 2 consecutive days.

Subgroup (b): infarct group, in which myocardial infarction was induced after 12 hours fasting by injection of isoprenaline subcutaneously in a dose of $85 \mathrm{mg} / \mathrm{kg}$ dissolved in $0.5 \mathrm{ml}$ saline for 2 consecutive days (Prasad, 2005).

Body weights were recorded at the beginning and at the end of the study. ECG of all rats were recorded basally before the first injection of isoprenaline, and again after 12 hours from the second injection of isoprenaline. Twelve hours fasting after the second dose of isoprenaline or saline, rats were sacrificed under thiopental anesthesia (120 $\mathrm{mg} / \mathrm{kg}$ I.P). Blood samples were collected by cardiac puncture. The blood samples were collected in tubes and left to clot for 2 hours at room temperature. Serum was obtained by centrifugation at $1000 \mathrm{rpm}$ for 20 minutes. Then, sera were stored at -20 until chemical analysis.

\section{I - Electrocardiography:}

Basal ECG ( lead II ) of each rat was recorded after 8 weeks for 30 seconds, then recorded again after induction of $\mathrm{Ml}$ by using computerized data acquisition system unit MP45 (BIOPAC Student Lab 3.7.5), electrode lead set and 3 electrodes per rat (Fig 1). The rats were anaesthetized by Ketamine $(0.2 \mathrm{mg} / \mathrm{g})$ and xylazine $(10 \mathrm{mg} / \mathrm{kg})$ injected intraperitoneally (Mutiso et al., 2014). Biopac electrode lead set (SS2LA/L) was plugged into channel 1 of MP45 acquisition unit. Gel was placed on the electrodes to make the contact with the skin better. The electrodes were placed on the medial surface of right forelimb and the hind limbs.

The following ECG variables were analyzed: QRS amplitude, QTC interval, and ST elevation. QTC was calculated using Bazzet's formula: QTc= QT Interval $/ \sqrt{ }$ (RR interval) (Mutiso et al., 2014). As QT interval is inversely correlated to heart rate, correction of QT interval is important to interpret QT interval independent of heart rate (Phan et al., 2015). The results were expressed in tables, and data were analyzed statistically.

II - Biochemical analysis:

Determination of serum total cholesterol, serum high density lipoprotein (HDL), low density lipoprotein (LDL) and triglyceride (TG) concentrations: by Enzymatic Colorimetric Kit that was purchased form (Sigma-Aldrich Co. Egypt). Determination of Creatine Kinase MB Isoenzyme (CK-MB): by Enzyme-linked Immunosorbent Assay Kit. For CK-MB, it is a sandwich enzyme immunoassay for in vitro quantitative measurement of CKMB in rat serum. It was purchased form (Sigma-Aldrich Co. Egypt).

\section{III - Histological Studies:}

At the end of this study, the heart was dissected and fixed in $10 \%$ neutral buffered formalin processed by standard procedure for paraffin embedding and serial sections were cut (5 ?). The sections were stained with hematoxylin and eosin.

\section{Statistical analysis}

The findings were expressed as mean \pm S.D. (mean \pm standard deviation). Statistical analyses were undertaken using independent One-way ANOVA with post-Hoc tukey test. We used the ttest for 2 samples assuming unequal variances, which confirmed the statistically significant difference $(P \leq 0.05)$. All the previous statistical analyses of data were carried out by SPSS software ver.17 (IBM,US). P-value $\leq 0.05$ was accepted statistically significant. All graphic representation of the data were performed with microsoft ${ }^{\circledR}$ Excelß for windows ${ }^{\circledR}$ (Microsoft Inc., USA).

\section{Results}

Body weights:

Effects of flaxseed oil and corn oil supplementation on body weight in high fat fed rats. 
The present study demonstrated that HFD caused a significant increase in body weight as compared with the control group $(P<0.001)$, whereas flaxseed oil supplementation with HFD caused significant reduction in body weight $(P<0.001)$, also corn oil supplementation with HFD caused significant reduction in body weight $(P<0.001)$ as compared with HFD fed group, but the body weight in both groups still significantly higher than the control (table 1).

\section{Serum lipid profile:}

Effects of flaxseed oil and corn oil supplementation with high fat fed rats on serum lipid profile. The present study revealed that HFD, as compared with the control group, produce significant elevation of serum, cholesterol, TG and LDL, but significantly decrease serum HDL. Whereas flaxseed oil supplementation, as compared with the HFD group, produced a significant reduction in serum cholesterol, TG and LDL, but these levels still significantly higher than the control. Meanwhile corn oils supplementation, as compared with the HFD group, produced a significant reduction in serum cholesterol and LDL, but these levels still significantly higher than the control (table 2).

\section{Effects of isoprenaline injection on serum lipid} profile.

It was found that 2 days after isoprenaline injection produced significant alteration in serum lipid profile in all groups as compared with values before isoprenaline injection. Serum cholesterol significantly increased in control group, in HFD group, in flaxseed oil supplemented group, in corn oil supplemented group. Also serum TG significantly increased in control group, in HFD fed group, in flaxseed oil supplemented group. Meanwhile LDL significantly increased in control group, in flaxseed oil supplemented group, in corn oil supplemented group. Whereas serum HDL significantly decreased in control group, in flaxseed oil supplemented group (table 2).
The present study demonstrated that 2 days after isoprenaline injection, HFD caused significant increase in, serum cholesterol level, serum TG level, serum LDL level as compared with the control group. Whereas 2 days after isoprenaline injection, flaxseed oil supplementation caused significant increase in serum cholesterol level, serum LDL level as compared with the control group. Also 2 days after isoprenaline injection corn oil supplementation caused significant increase in, serum cholesterol level, serum LDL level as compared with the control group (table 2).

But as compared with HFD group it was demonstrated that 2 days after isoprenaline injection, both flaxseed oil supplementation and corn oil supplementation caused significant decrease in, serum cholesterol level, serum TG, serum LDL level (table 2).

\section{Serum creatine kinase level:}

The present study revealed that 2 days after isoprenaline injection caused significant increase in CK-MB level in all groups as compared with before injection (table 1).

As compared with the control group it was found that the 2 days after isoprenaline injection, HFD caused significant increase in CK-MB level, but flaxseed oil supplementation caused significant decrease in CK-MB level. Whereas as compared with HFD fed group, flaxseed oil supplementation caused significant decrease in CK-MB level from $287.66 \pm 8.82 \mathrm{U} / \mathrm{L}$ to $164.16 \pm 10.60 \mathrm{U} / \mathrm{L}$, also corn oil supplementation caused significant decrease in CK-MB level from $287.66 \pm 8.82 \mathrm{U} / \mathrm{L}$ to $196.16 \pm 17.62 \mathrm{U} / \mathrm{L}$ (table 1 ).

\section{ECG parameters:}

The present study demonstrated that 2 days after isoprenaline injection caused significant, decrease in QRS amplitude, prolongation of QTC interval, but caused significant increase in ST segment elevation, in many groups. In the control 
group, isoprenaline injection decrease QRS amp from $0.31 \pm 0.08 \mathrm{mV}$ to $0.16 \pm 0.005 \mathrm{mV}$, prolong QTc interval from $0.161 \pm 0.01 \mathrm{sec}$ to $0.217 \pm 0.03$ $\mathrm{sec}$ and it increase ST segment elevation from $0.013 \pm 0.005 \mathrm{mV}$ to $0.10 \pm 0.013 \mathrm{mV}$. Also in HFD fed group, isoprenaline injection decrease QRS amp from $0.20 \pm 0.008 \mathrm{mV}$ to $0.08 \pm 0.008 \mathrm{mV}$, prolong QTc interval from $0.172 \pm 0.02 \mathrm{sec}$ to $0.236 \pm 0.00 \mathrm{sec}$ and it increase ST segment elevation from $0.018 \pm 0.040 \mathrm{mV}$ to $0.08 \pm 0.005 \mathrm{mV}$ (table 3), (Fig 2).

As compared with the control group, ECG parameters 2 days after isoprenaline injection, there is no significant difference between the control group and HFD fed group. But flaxseed oil supplementation caused significant, shortening of QTC interval from $0.217 \pm 0.03 \mathrm{sec}$ to $0.172 \pm 0.01 \mathrm{sec}$, and decrease in ST segment elevation from 0.10 $\pm 0.013 \mathrm{mV}$ to $0.023 \pm 0.036 \mathrm{mV}$. Whereas corn oil supplementation caused only significant decrease in ST segment elevation from $0.10 \pm 0.013 \mathrm{mV}$ to $0.030 \pm 0.036 \mathrm{mV}$ (table 3) (Fig 2).

While as compared with the HFD fed group, flaxseed oil supplementation caused significant, increase in QRS amp from $0.08 \pm 0.008 \mathrm{mV}$ to 0.23 $\pm 0.04 \mathrm{mV}$, shortening of QTc interval from 0.236 $\pm 0.00 \mathrm{sec}$ to $0.172 \pm 0.01 \mathrm{sec}$, and decrease in ST segment elevation from $0.08 \pm 0.005 \mathrm{mV}$ to 0.023 $\pm 0.036 \mathrm{mV}$. Whereas corn oil supplementation caused only significant decrease in ST segment elevation from $0.08 \pm 0.005 \mathrm{mV}$ to $0.030 \pm 0.036$ $\mathrm{mV}$ (table 3), (Fig 3).

\section{Cardiac histopathological changes:}

Histopathology of the cardiac muscle in a non infarct rat fed HFD, shows moderate inflammation (infiltration by mixed inflammatory cells and congested capillary) and vacuolization in the cardiac muscle (vacuoles means clear areas in the cytoplasm most probably fat dissolved). Whereas HFD supplemented with flaxseed oil and that supplemented with corn oil, induce only mild inflammation in the cardiac muscle.

In the present study it was demonstrated that, 2 days after isoprenaline injection caused cardiac muscle infarction in both control group and HFD fed group, demonstrated by marked inflammation in the cardiac muscle (marked infiltration by mixed inflammatory cells and congested capillary). Whereas HFD fed group shows vacuolization and vasculitis (prominent endothelium, infiltration of the wall by inflammatory cells mainly lymphocyte) (fig 4).

HFD fed rats supplemented with flaxseed oil, isoprenaline injection caused moderate inflammation in the cardiac muscle (infiltration by mixed inflammatory cells) and normal blood vessels. But in HFD fed rats supplemented with corn oil, isoprenaline injection caused marked inflammation in the cardiac muscle and prominent vasculitis (fig 4). 
Table (1): Effect of vegetable oils, flaxseed and corn oils on body weight and serum CK$\mathrm{MB}$ before and 2 days after isoprenline induced acute myocardial infarction

\begin{tabular}{|c|c|c|c|c|c|}
\hline & & Control & HFD & HFD + flax & HFD + Corn \\
\hline \multirow{2}{*}{$\begin{array}{c}\text { Body weight } \\
\text { (gm) }\end{array}$} & Onset & $\begin{array}{c}131.5 \\
\pm 11.04\end{array}$ & $\begin{array}{c}142.66 \\
\pm 12.69\end{array}$ & $\begin{array}{l}137.16 \\
\pm 17.71\end{array}$ & $\begin{array}{l}134.33 \\
\pm 24.97\end{array}$ \\
\hline & Final & $\begin{array}{c}206.00 \\
\pm 10.11 *\end{array}$ & $\begin{array}{c}308.41 \\
\pm 21.13^{* a}\end{array}$ & $\begin{array}{c}235.66 \\
\pm 19.16^{* a, b}\end{array}$ & $\begin{aligned} & 258.00 \\
\pm & 28.38^{*} \mathrm{a}, \mathrm{b}\end{aligned}$ \\
\hline \multirow{2}{*}{$\begin{array}{c}\text { CK-MB } \\
\text { (U/L) }\end{array}$} & Basal & $\begin{array}{l}19.66 \\
\pm 3.66\end{array}$ & $\begin{array}{c}24.33 \\
\pm 3.93\end{array}$ & $\begin{array}{c}20.00 \\
\pm 5.72\end{array}$ & $\begin{array}{l}20.66 \\
\pm 2.16\end{array}$ \\
\hline & (2 days) & $\begin{array}{c}221.50 \\
\pm 13.45^{*}\end{array}$ & $\begin{array}{c}287.66 \\
\pm 8.82 * \mathrm{a}\end{array}$ & $\begin{array}{c}164.16 \\
\pm 10.60 * \mathrm{a}, \mathrm{b}\end{array}$ & $\begin{array}{c}196.16 \\
\pm 17.62 * \mathrm{~b}\end{array}$ \\
\hline
\end{tabular}

HFD = high fat diet group, HFD + flax = high fat diet flaxseed oil supplemented group, HFD + corn $=$ high fat diet corn oil supplemented group. $\mathrm{CK}=$ creatine kinase. ${ }^{*} \mathrm{P}$ value $(<0.05)$ as compared with basal record, ${ }^{\text {a }}$ P1 value $(<0.05)$ as compared with control group, ${ }^{\mathrm{b}} \mathrm{P} 2$ value $(<0.05)$ as compared with HFD group, ${ }^{\mathrm{C}} \mathrm{P} 3$ value $(<0.05)$ as compared with HFD+ flax group.

Table (2): Effect of vegetable oils, flaxseed and corn oils on serum lipid profile before and 2 days after isoprenaline induced acute myocardial infarction

\begin{tabular}{|c|c|c|c|c|c|c|c|c|}
\hline & \multicolumn{2}{|c|}{ Control } & \multicolumn{2}{|c|}{ HFD } & \multicolumn{2}{|c|}{ HFD + flax } & \multicolumn{2}{|c|}{ HFD + Corn } \\
\hline & Before & (2days) & Before & (2days) & Before & (2days) & Before & (2days) \\
\hline $\begin{array}{l}\text { Cholesterol } \\
(\mathrm{mg} / \mathrm{dl})\end{array}$ & $\begin{array}{c}136.01 \\
\pm 3.80\end{array}$ & $\begin{array}{l}217.00 \\
\pm 3.46^{*}\end{array}$ & $\begin{array}{c}275.50 \\
\pm 11.94^{\text {a }}\end{array}$ & $\begin{array}{c}308.16 \\
\pm 10.94 * a\end{array}$ & $\begin{array}{c}230.33 \\
\pm 4.22^{\mathrm{a}, \mathrm{b}}\end{array}$ & $\begin{array}{c}254.16 \\
\pm 5.41 * \mathrm{a}, \mathrm{b}\end{array}$ & $\begin{array}{c}237.00 \\
\pm 2.36^{\mathrm{a}, \mathrm{b}}\end{array}$ & $\begin{array}{c}261.83 \\
\pm 7.13 * a, b\end{array}$ \\
\hline $\begin{array}{l}\text { HDL-CL } \\
(\mathrm{mg} / \mathrm{dl})\end{array}$ & $\begin{array}{l}48.16 \\
\pm 2.63\end{array}$ & $\begin{array}{c}28.83 \\
\pm 2.40^{*}\end{array}$ & $\begin{array}{l}31.33 \\
\pm 2.42^{\mathrm{a}}\end{array}$ & $\begin{array}{l}32.50 \\
\pm 3.93\end{array}$ & $\begin{array}{c}37.33 \\
\pm 2.94^{\mathrm{a}}\end{array}$ & $\begin{array}{c}28.50 \\
\pm 2.58^{*}\end{array}$ & $\begin{array}{c}31.16 \\
\pm 3.65^{\mathrm{a}}\end{array}$ & $\begin{array}{l}26.50 \\
\pm 3.27\end{array}$ \\
\hline $\begin{array}{l}\text { LDL-CL } \\
(\mathrm{mg} / \mathrm{dl})\end{array}$ & $\begin{array}{l}67.51 \\
\pm 4.65\end{array}$ & $\begin{array}{l}152.58 \\
\pm 4.67^{*}\end{array}$ & $\begin{array}{c}206.26 \\
\pm 12.25^{\text {a }}\end{array}$ & $\begin{array}{l}231.86 \\
\pm 11.60^{\mathrm{a}}\end{array}$ & $\begin{array}{c}160.90 \\
\pm 6.47^{\mathrm{a}, \mathrm{b}}\end{array}$ & $\begin{array}{c}190.00 \\
\pm 5.46^{* a, b}\end{array}$ & $\begin{array}{c}169.53 \\
\pm 4.59^{\mathrm{a}, \mathrm{b}}\end{array}$ & $\begin{array}{c}197.70 \\
\pm 7.77 * \mathrm{a}, \mathrm{b}\end{array}$ \\
\hline $\mathrm{TG}(\mathrm{mg} / \mathrm{dl})$ & $\begin{array}{c}101.66 \\
\pm 9.54\end{array}$ & $\begin{array}{l}178.00 \\
\pm 2.82 *\end{array}$ & $\begin{array}{l}189.50 \\
\pm 4.67^{\mathrm{a}}\end{array}$ & $\begin{array}{l}219.00 \\
\pm 4.42 * \mathrm{a}\end{array}$ & $\begin{array}{c}160.50 \\
\pm 5.68^{\mathrm{a}, \mathrm{b}}\end{array}$ & $\begin{array}{c}178.33 \\
\pm 5.16^{* b}\end{array}$ & $\begin{array}{c}181.50 \\
\pm 6.83^{\mathrm{a}, \mathrm{c}}\end{array}$ & $\begin{array}{l}188.16 \\
\pm 7.41^{\mathrm{b}}\end{array}$ \\
\hline
\end{tabular}

HFD $=$ high fat diet group, HFD + flax = high fat diet flaxseed oil supplemented group, HFD + corn $=$ high fat diet corn oil supplemented group. HDL-CL $=$ high density lipoprotein cholesterol, LDL-CL = low density lipoprotein cholesterol, TG $=$ triglyceride. ${ }^{*} \mathrm{P}$ value $(<0.05)$ as compared with basal record, ${ }^{\text {a }} \mathrm{P} 1$ value $(<0.05)$ as compared with control group, ${ }^{\mathrm{b}} \mathrm{P} 2$ value $(<0.05)$ as compared with HFD group, ${ }^{\mathrm{c}} \mathrm{P} 3$ value $(<0.05)$ as compared with HFD+ flax group. 
Table (3): Effect of vegetable oils, flaxseed and corn oils on ECG parameters before and 2 days after isoprenaline induced acute myocardial infarction

\begin{tabular}{|c|c|c|c|c|c|c|c|c|}
\hline \multirow{2}{*}{} & \multicolumn{2}{|c|}{ Control } & \multicolumn{2}{c|}{ HFD } & \multicolumn{2}{c|}{ HFD + flax } & \multicolumn{2}{c|}{ HFD + Corn } \\
\cline { 2 - 8 } & Before & (2days) & Before & (2days) & Before & (2days) & Before & (2days) \\
\hline $\begin{array}{c}\text { QRS } \\
\text { amplitude } \\
\text { (mV) }\end{array}$ & $\begin{array}{c}0.31 \\
\pm 0.08\end{array}$ & $\begin{array}{c}0.16 \\
\pm 0.005^{*}\end{array}$ & $\begin{array}{c}0.20 \\
\pm 0.008\end{array}$ & $\begin{array}{c}0.08 \\
\pm 0.008^{*}\end{array}$ & $\begin{array}{c}0.27 \\
\pm 0.05\end{array}$ & $\begin{array}{c}0.23 \\
\pm 0.04^{\mathrm{b}}\end{array}$ & $\begin{array}{c}0.30 \\
\pm 0.01\end{array}$ & $\begin{array}{c}0.18 \\
\pm 0.05^{*}\end{array}$ \\
\hline $\begin{array}{c}\text { QTc } \\
\text { interval } \\
(\mathbf{s e c})\end{array}$ & 0.161 & 0.217 & 0.172 & 0.236 & 0.161 & 0.172 & 0.172 & 0.197 \\
\pm 0.01 & $\pm 0.03^{*}$ & \pm 0.02 & $\pm 0.00^{*}$ & \pm 0.02 & $\pm 0.01^{\mathrm{a}, \mathrm{b}}$ & \pm 0.004 & \pm 0.02 \\
\hline $\begin{array}{c}\text { ST } \\
\text { elevation } \\
(\mathbf{m V})\end{array}$ & 0.013 & 0.10 & 0.018 & 0.08 & 0.015 & 0.023 & 0.015 & 0.030 \\
\pm 0.005 & $\pm 0.013^{*}$ & \pm 0.040 & $\pm 0.005^{*}$ & \pm 0.012 & $\pm 0.036^{\mathrm{a}, \mathrm{b}}$ & \pm 0.025 & $\pm 0.036^{\mathrm{a}, \mathrm{b}}$ \\
\hline
\end{tabular}

HFD $=$ high fat diet group, HFD + flax $=$ high fat diet flaxseed oil supplemented group, HFD + corn $=$ high fat diet corn oil supplemented group. QTc $=$ corrected QT interval, ST $=\mathrm{ST}$ segment. *P value $(<0.05)$ as compared with basal record, ${ }^{a} \mathrm{P} 1$ value $(<0.05)$ as compared with control group, ${ }^{\mathrm{b}} \mathrm{P} 2$ value $(<0.05)$ as compared with HFD group, ${ }^{\mathrm{c}} \mathrm{P} 3$ value $(<0.05)$ as compared with HFD+ flax group.

\section{Figures}
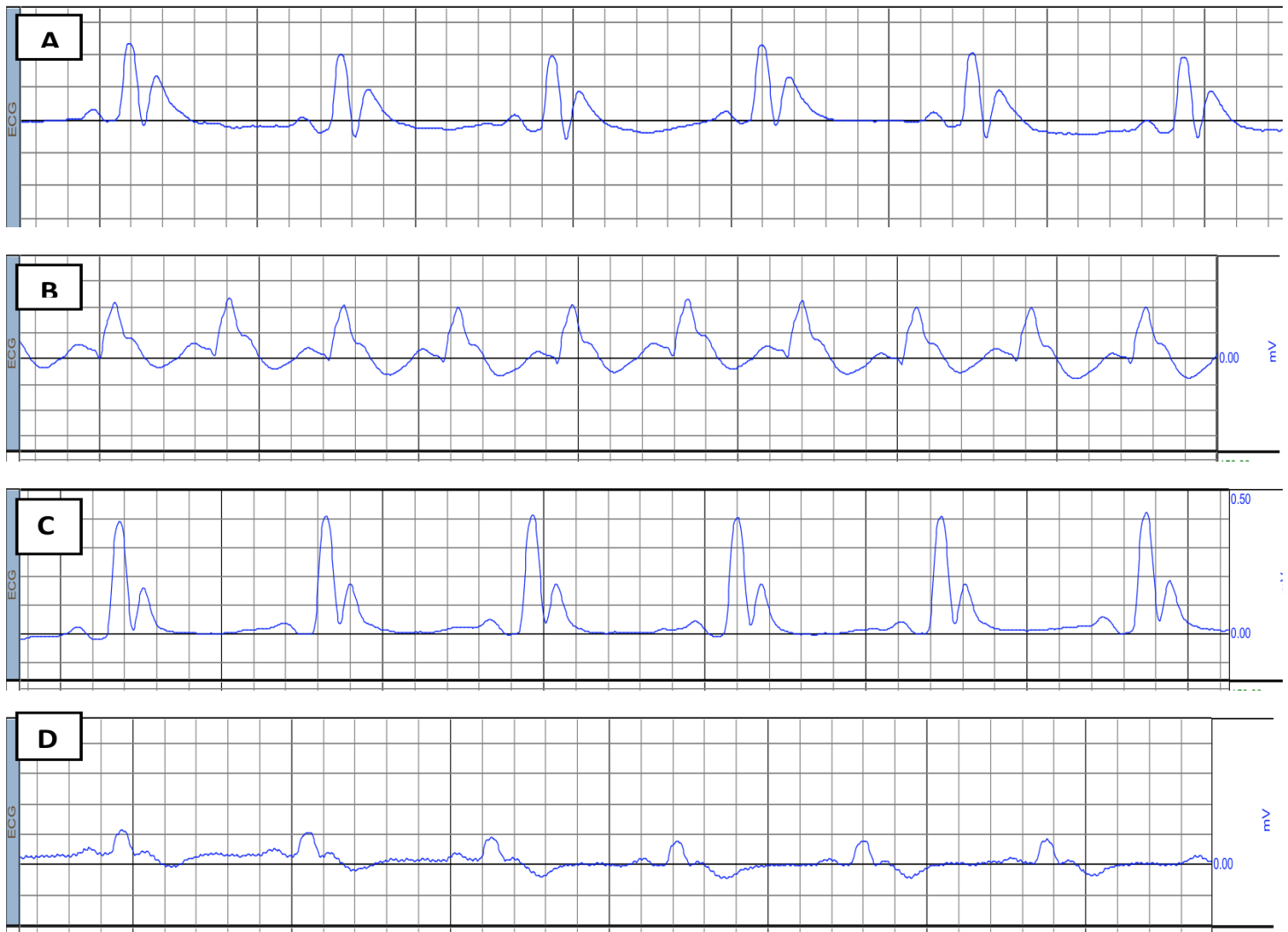

Figure (1): ECG record traces of control group A) before and B) 2 days after isoprenaline injection. ECG of HFD fed group C) before and D) 2 days after isoprenaline injection 

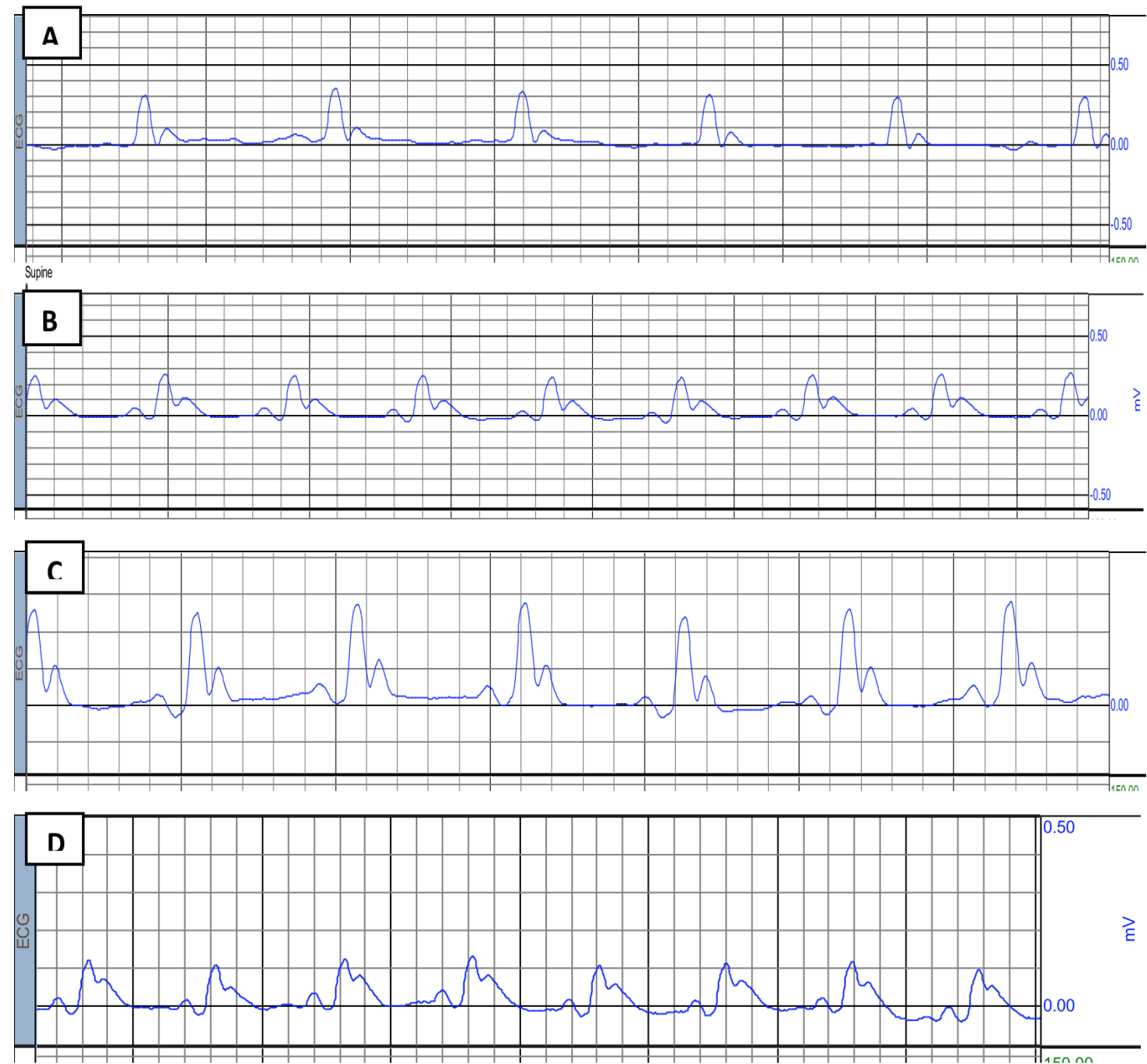

Figure (2): ECG of HFD fed flaxseed oil supplemented group A) before and B) 2 days after isoprenaline injection. ECG of HFD fed corn oil supplemented group C) before and D) 2 days after isoprenaline injection. 

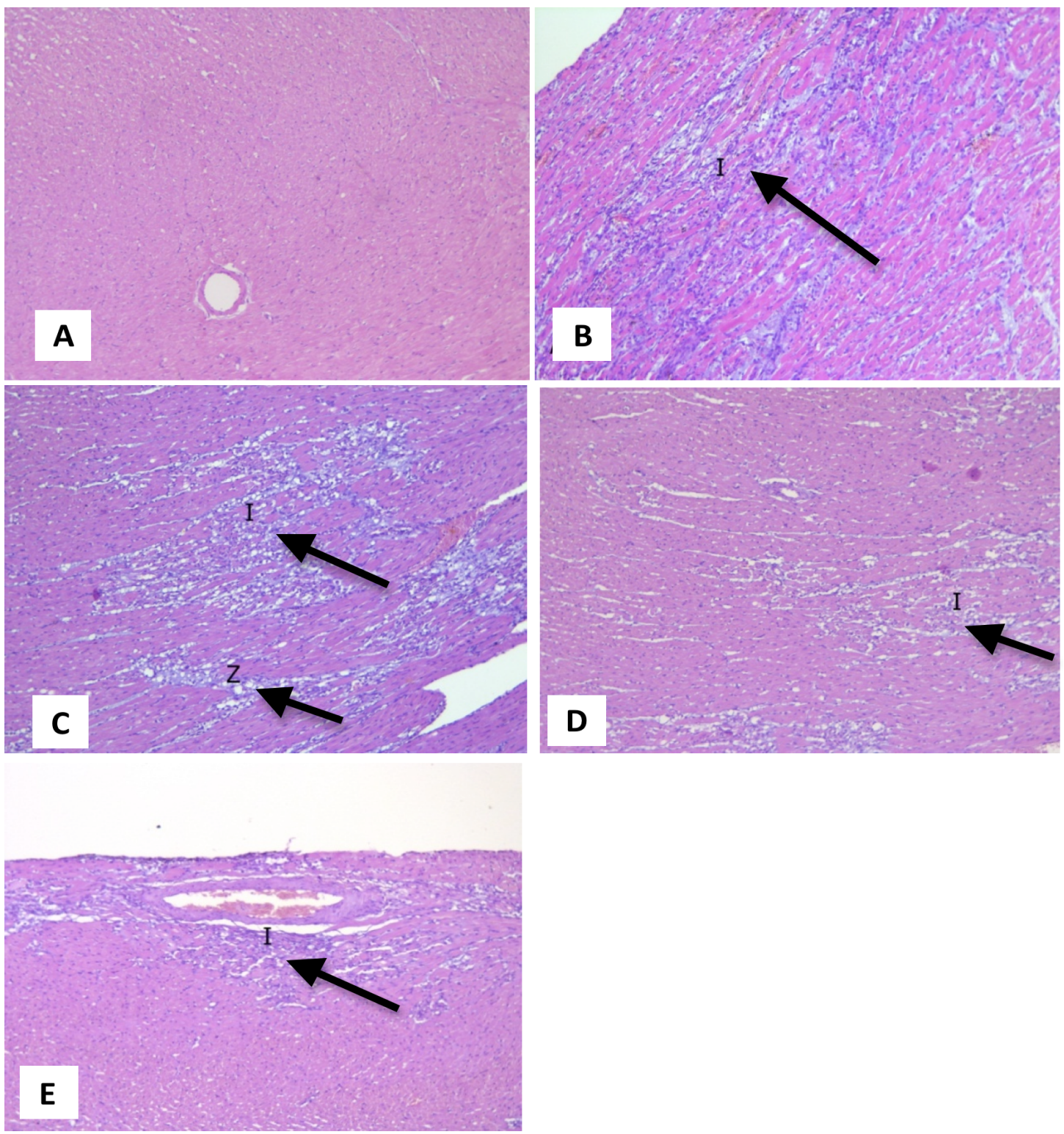

Figure (3): ): Histopathology of the cardiac muscle (Hx \& $\left.\left.\mathrm{E}^{*} 100\right), \mathrm{A}\right)$ a non-infarct control rat: shows normal architecture of the cardiac muscle. B) infarct control rat: shows marked inflammation in the cardiac muscle. C) infarct rat fed HFD: shows marked inflammation in the cardiac muscle. D) infarct rat fed HFD supplemented with flaxseed oil: shows moderate inflammation in the cardiac muscle. E) infarct rat fed HFD supplemented with corn oil: shows marked inflammation in the cardiac muscle. (I) refers to inflammation (infiltration by mixed inflammatory cells and congested capillary) and $(Z)$ refers to vacuolization (vacuoles means clear areas in the cytoplasm most probably fat dissolved). 


\section{Discussion}

The present study demonstrated that body weights in rats fed a high fat diet supplemented with flaxseed oil and rats fed a high fat diet supplemented with corn oil were significantly lowered as compared to rats fed on high fat diet. It means that flaxseed and corn oils supplementation may help in reducing the risk of obesity. These results are consistent with Rasmy (2007), who demonstrated that flaxseed oil supplementations reduced significantly weight gain in rats fed a highly saturated fatty diet.

The present study demonstrated that high fat diet led to increase in the serum levels of total cholesterol, LDL and triglycerides. Also, high fat diet caused histopathological changes in the heart as cellular vacuolization and moderate inflammation. These results can be explained by impairment of ?-oxidation and mitochondrial function. It results in increase the production of reactive oxygen species (ROS) and eventually lead to inflammation in the myocardium (Guzzardi \& lozzo, 2011). Whereas, flaxseed oil supplementation significantly reduced total cholesterol, LDL and triglycerides levels as compared to rats fed with high fat. In agreement with these results, Hassan et al. (2012) demonstrated that flaxseed reduced the cholesterol level relating to greater fecal content of lipid. Also flaxseed oil supplementation reduced the histopathological finding of inflammation in the heart as compared to rats fed a high fat diet.

Omega 3 fatty acids present in flaxseed oil enhance cholesterol excretion via bile, resulting in depletion of hepatic cholesterol pool (Rasmy, 2007). Additionally, ALA rich diet reduces hepatic lipid accumulation either by stimulating $\beta$-oxidation or by suppressing fatty acid synthesis (Murase et al., 2005). Ide et al. (2000) stated that flaxseed oil could have its protective role, probably through functioning as a better substrate for mitochondrial and peroxisomal $\beta$-xidation. In agreement with Prasad et al. (2000), who stated that flaxseed oil lowers TAG levels in rats fed a high saturated fat diet, which might be due to the increased activity of lipoprotein lipase.

In previous studies, n-3 PUFA has been considered to reduce TG levels via regulating peroxisome proliferator - activated receptor alpha (PPAR?) and Sterol regulatory element-binding proteins 1c (SREBP-1c). They were considered important regulators of hepatic fatty a cid catabolism and synthesis (Tanaka et al., 2010). Also, other study showed that flaxseed oil resulted in elevated mRNA and protein expression of PPAR $\alpha$ and reduced SREBP-1 (Han et al., 2015).

In the current study, corn oil significantly decreases total cholesterol, LDL-CL and TG as compared to rats fed a high fat diet. In agreement with these results, Dauqan et al. (2011) reported that rats fed corn oil showed significant decrease in total cholesterol level and LDL-CL as compared with the control group. These results are consistent with Mandimika et al. (2012), who reported that rats fed corn oil showed significant decrease in both total cholesterol and TG. The hypolipidemic effect of corn oil may be due to alteration of hepatic expression of lipid metabolism - related genes, so influencing lipid synthesis and enhancing cholesterol catabolism (Rideout et al., 2008). The possible mechanism for the hypolipidemic action of corn oil is an induction in expression of carnitine palmitoyltransferase I (CPT1a) gene in the liver. CPT1a is considered a rate limiting gene in fatty acids B- oxidation; it encodes a protein which stimulates carnitine synthesis, directing fatty acids toward B- oxidation instead of lipid synthesis. It was noticed that, when CPT1a expression is decreased, cholesterol and TG levels are increased (Mandimika et al., 2012). Also, phytosterol content of corn oil may reduce GIT cholesterol ab- 
sorption, so lower cholesterol levels (Mandimika et al., 2012).

Isoprenaline-treated groups showed high serum levels of CK-MB, ECG changes and histopathological changes. ECG changes presented in decreasing QRS complex amplitude, prolongation of QTC interval and elevated ST segment. These ECG changes were confirmed by histopathological changes in the heart like presence of severe inflammation, congestion, hemorrhage and vasculitis. A standard marker for estimation of myocardial injury is CK-MB, which leaks from myocardium after damaging contractile fibers and increasing sarcoplasmic permeability (Mair et al., 1994). The cause of ST elevation is due to the presence of current of injury in the damaged cardiomyocytes. Injured myocardium results in persistent depolarization and a current flows between the pathologically depolarized and normal polarized parts. This current leads to incomplete repolarization of cardiac muscle resulting in depression of (TP segment). So, it is a depression of the baseline voltage (TP segment) rather than ST segment elevation (Coppola et al., 2013). Presence of edema and inflammation in the myocardium may be the cause of attenuated QRS complex amplitude and prolonged QTc interval (Derbali et al., 2015). The consecutive loss of cell membrane potential in injured myocardium may account for these ECG changes (Punithavathi \& Stanely Mainzen Prince, 2011).

The pathogenesis of myocardial infarction has not been clearly understood. It was evident in previous studies, that high dose of isoprenaline leads to myocardial ischemia, necrosis, hypoxia, resulting in myocardial infarction. Isoprenaline induced myocardial infarction is a well- known model for evaluating cardioprotective drugs (Karthick \& Prince, 2006). There are several mechanisms explaining the cardiotoxic effect of high doses of isoprenaline like; hypoxia and ischemia, coronary in- sufficiency, reduced levels of high energy phosphate stores, electrolyte disturbance, alternation in metabolism, intracellular calcium overload and oxidative stress (Dhalla et al., 1992). One of the most important apoptosis executors is caspase 3 , increasing the expression of caspase- 3 gene may lead to ischemic apoptosis in the myocardium in AMI, also hypoxia in AMI leads to enhance the secretion of tumor necrosis factor (TNF- $\alpha$ ) leading to induce inflammation and damage the myocardium (Sun et al., 2015).

Concerning electrocardiographic parameters, it was found in the present study that flaxseed oil increased QRS amplitude but significantly, shortened QTc interval and decreased ST segment elevation as compared to control rats and to rats fed a high fat diet. These results are consistent with Derbali et al. (2015), who reported that flaxseed oil reduced significantly ST elevation as compared to control. These findings could be explained by flaxseed oil supplementation has cardioprotective effect as it reduced AMI induced CK$\mathrm{MB}$ level elevation as compared to the control and rats fed a high fat diet respectively. In agreement with Derbali et al. (2015), who reported that flaxseed oil reduced significantly CK-MB as compared to control. Also in AMI flaxseed oil supplementation reduced inflammation and congestion in myocardium as compared to both control and high fat diet group, also flaxseed oil prevented vascuilitis, which was presented in the two other subgroups. The potential cardioprotective effect may be due the antioxidant activity of flaxseed oil (Zanwar et al. 2010).

Also, it was reported that flaxseed oil and plant sterols supplements reduced the expression of vascular cell adhesion molecule (VCAM-1), IL1 and IL6 (Han et al., 2015). This anti-inflammatory effect of flaxseed oil can be attributed to the reduction of many inflammatory markers such as; TNF- $\alpha$, IL-1 $\beta$, thromboxane B5, prostaglandin E5 
and CRP (Bloedon et al., 2008; Hallund et al., 2008). Novel bioactive lipid mediators of omega 3 PUFA are discovered recently such as resolvins, protectins and maresins that have antiinflammatory effects. Resolvin E1 (RvE1) is synthesized from EPA. Leukocytes infiltration to the inflammed area is reduced by RvE1, suppressing cytokines production and resolving the inflammation (Endo \& Arita, 2016). In addition to the antiinflammatory and the antioxidant effects, the protective role of flaxseed oil can be explained by its hypolipidemic effect, as hypercholesterolemia is associated with increased oxidative stress related to lipid peroxidation. Moreover, increased oxidized LDL contributes as a major factor in the vascular damage, as it is precipitated on the wall of blood vessels (Adaramoye, 2008).

In this study, in AMI corn oil supplementation showed significant decrease in ST segment elevation as compared to control and rats fed a high fat diet. Corn oil may not be as protective as flaxseed oil, as in ECG record corn oil supplementation insignificantly increase QRS amplitude, and insignificantly decreases QTc interval as compared to rats fed a high fat diet. These electrocardiographic results were supported by a significant decrease in CK-MB in rats fed a high fat diet supplemented with corn oil as compared to rats fed a high fat diet and insignificant decrease in CK-MB as compared to control. Corn oil may protect to some extent from cardiovascular diseases, as it is one of the richest natural source of vitamin $E$ $(62.01 \mathrm{mg} / 100 \mathrm{~g}$ oil), and so helps in reduction of ROS. Corn oil supplementation also decreases proinflammatory markers as IL- 6 and IFN- $\alpha$ As well as, corn oil lowers LDL-cholesterol, total cholesterol and triglycerides (Si et al., 2014). Corn oil is enriched with phytosterols, which reduce cholesterol levels, subsequently decreasing heart diseases (Hicks \& Moreau, 2001). Moreover, corn oil is converted inside the body into gamma linolenic acid ( $\alpha$-linolenic) (GLA) (Stoffel et al., 2008), which is believed to reduce platelets aggregation in the blood vessels. It may be due to reducing the activity of thromboxane in blood, so reducing the incidence of heart attacks (Riaz et al., 2009). It was reported that GLA regulates the inflammatory nuclear factor-kappa B preventing it from switching on genes for inflammatory cytokines in the nuclei of cells (Chang et al., 2010), so reduce the risk of cardiovascular diseases.

This study revealed that flaxseed oil is more beneficial than corn oil in prevention of hyperlipidemia and acute myocardial infarction. Flaxseed oil led to significant increase in QRS amplitude, significant shortening of QTc interval and less ST elevation. Regarding biochemical studies, flaxseed oil supplementation caused better improvement in lipid profile and much decrease in CK-MB. Moreover, in histopathological studies, flaxseed alleviated the inflammation and congestion in myocardial infarction.

Flaxseed has higher content of $\omega-3 \alpha$-linolenic acid (ALA) that helps in prevention and treatment of many diseases. As ALA is metabolized inside the body, it is converted into docosahexaenoic acid (DHA) and eicosapentaenoic acid (EPA); which are known for their healthy properties. It reduces the risk in CVD, arthritis, diabetes osteoporosis, cancer, neurological disorders and autoimmune diseases (Simopoulos, 2000; Gogus \& Smith, 2010). The cardioprotective effect of flaxseed oil is due to its high content of omega 3 fatty acids that have antioxidant, anti- inflammatory and hypolipidemic effects. One of the underlying cardioprotective mechanisms may be the changing of physiochemical properties in the cell membrane. Omega 3 incorporation in the cell membrane can alter membrane protein signaling (Mozaffarian \& Wu, 2011). Supplementation of omega 3 fatty acids is thought to be antiarrhythmic, as it can stabilize the electrical activity of cardiac muscle. Also it was reported that 
omega 3 fatty acids supplementation exert antithrombotic effect, as EPA inhibit thromboxane A2 synthesis resulting in reducing the platelet aggregation and vasoconstriction, and omega 3 fatty acids supplementation led to decrease fibrinogen and increase tissue plasminogen activator (Jain et al., 2015). Omega 3 fatty acids can improve arterial dilatation and the mechanical function of the heart (Mozaffarian \& Wu, 2011). Also, omega 3 fatty acids play an important role in protection against atherosclerosis, as it reduces platelet derived growth factor which is responsible for chemoattraction of macrophages and smooth muscle cells in the atherosclerotic plaque (Jain et al., 2015).

On the other hand, corn oil is a rich source of omega $6(\omega-6)$ fatty acids linoleic acid (LA) (Si et al., 2014) which is the precursor of arachidonic acid (AA). Omega 6 pathway starts with linoleic acid (LA) that is metabolized to $\gamma$-linolenic (Stoffel et al., 2008), which protects against many diseases. Some studies demonstrate that $\gamma$-linolenic fight against obesity (Schirmer \& Phinney, 2007), and diabetes (Das, 2005). Many studies stated that, GLA reduces platelets aggregation within small blood vessels. This is due to reduction of the activity of thromboxane in blood which minimizes the incidence of strokes and heart attack (Riaz et al., 2009).

In conclusion: Flaxseed and corn oils exhibit cardioprotective effects in attenuation of acute myocardial infarction in rats fed a high fat diet. Flaxseed oil has more cardioprotective effects may be attributed to its higher content of omega 3 fatty acids.

\section{References}

Adaramoye, O. (2008) : Lipid-lowering effects of methanolic extract of vernonia amygdalina leaves in rats fed on high cholesterol diet. Vas- cular Health and Risk Management, 4: (1), 235-241.

Barcelo-Coblijn, G. and Murphy, E. (2009). Alphalinolenic acid and its conversion to longer chain $\mathrm{n}-3$ fatty acids: Benefits for human health and a role in maintaining tissue n-3 fatty acid levels. Progress in Lipid Research, 48: (6), 355-374.

Bloedon, L.; Balikai, S.; Chittams, J.; Cunnane, S.; Berlin, J.; Rader, D., et al. (2008). Flaxseed and cardiovascular risk factors: Results from a double blind, randomized, controlled clinical trial. Journal of the American College of Nutrition, 27: (1), 65-74.

Burghardt, P.; Kemmerer, E.; Buck, B.; Osetek, A.; Yan, C.; Koch, L., et al. (2010). Dietary n-3: $n-6$ fatty acid ratios differentially influence hormonal signature in a rodent model of metabolic syndrome relative to healthy controls. Nutrition \& Metabolism, 7: (1), 53.

Calder, P. (2003). N-3 polyunsaturated fatty acids and inflammation: From molecular biology to the clinic. Lipids, 38: (4), 343-352.

Calder, P. (2004). N-3 fatty acids and cardiovascular disease: Evidence explained and mechanisms explored. Clinical science, 107: (1), 111.

Calder, P. and Yaqoob, P. (2009). Omega-3 (n-3) fatty acids, cardiovascular disease and stability of atherosclerotic plaques. Cellular and molecular biology (Noisy-le-Grand, France), 56: (1), 28-37.

Chang, C.; Sun, H.; Lii, C.; Chen, H.; Chen, P. and Liu, K. (2010). Gamma-linolenic acid inhibits inflammatory responses by regulating NF$\mathrm{KB}$ and AP-1 activation in lipopolysaccharideinduced RAW 264.7 macrophages. Inflammation, 33: (1), 46-57.

Coppola, G.; Carità, P.; Corrado, E.; Borrelli, A.; Rotolo, A.; Guglielmo, M., et al. (2013). ST segment elevations: Always a marker of acute myocardial infarction? Indian Heart Journal, 65: (4), 412-423.

Das, U. (2005). A defect in the activity of ?6 and 
?5 desaturases may be a factor predisposing to the development of insulin resistance syndrome. Prostaglandins, Leukotrienes and Essential Fatty Acids, 72: (5), 343-350.

Dauqan, E.; Sani, H.; Abdullah, A. and Kasim, Z. (2011). Effect of different vegetable oils (red palm olein, palm olein, corn oil and coconut oil) on lipid profile in rat. FNS, 02: (04), 253-258.

Derbali, A.; Mnafgui, K.; Affes, M.; Derbali, F.; Hajji, R.; Gharsallah, N., et al. (2015). Cardioprotective effect of linseed oil against isoproterenol-induced myocardial infarction in wistar rats: A biochemical and electrocardiographic study. Journal of Physiology and Biochemistry, 71: (2), 281-288.

Dhalla, N.; Dixon, I.; Suzuki, S.; Kaneko, M.; Kobayashi, A. and Beamish, R. (1992). Changes in adrenergic receptors during the development of heart failure. Molecular and Cellular Biochemistry, 114: (1-2).

Dupasquier, C.; Dibrov, E.; Kneesh, A.; Cheung, P.; Lee, K.; Alexander, H., et al. (2007). Dietary flaxseed inhibits atherosclerosis in the LDL receptor-deficient mouse in part through antiproliferative and anti-inflammatory actions. AJP: Heart and Circulatory Physiology, 293: (4), H2394-H2402.

Endo, J. and Arita, M. (2016). Cardioprotective mechanism of omega-3 polyunsaturated fatty acids. Journal of Cardiology, 67: (1), 22-27.

Gaby, A. (2010). Nutritional treatments for acute myocardial infarction. Altern Med Rev, 15: (2), 113-123.

Garg, A. and Simha, V. (2007). Update on dyslipidemia. The Journal of Clinical Endocrinology \& Metabolism, 92: (5), 1581-1589.

Gogus, U. and Smith, C. (2010). N-3 omega fatty acids: A review of current knowledge. International Journal of Food Science \& Technology, 45: (3), 417-436.

Guzzardi, M. and lozzo, P. (2011). Fatty heart, cardiac damage, and inflammation. The Review of Diabetic Studies, 8: (3), 403-417.

Hallund, J.; Tetens, I.; Bugel, S.; Tholstrup, T. and
Atorvastatin and metformin in MetS Nehal $\mathrm{H}$ et al. 60

Bruun, J. (2008). The effect of a lignan complex isolated from flaxseed on inflammation markers in healthy postmenopausal women. Nutrition, Metabolism and Cardiovascular Diseases, 18: (7), 497-502.

Han, H.; Yan, P.; Chen, L.; Luo, C.; Gao, H.; Deng, Q., et al. (2015). Flaxseed oil containing ?-linolenic acid ester of plant sterol improved atherosclerosis in ApoE deficient mice. Oxidative Medicine and Cellular Longevity, 2015: 117.

Hassan, A.; Rasmy, N.; Foda, M. and Bahgaat, W. (2012). Production of functional biscuits for lowering blood lipids. World J Dairy Food Sci, 7: (1), 01-20.

Hicks, K. and Moreau, R. (2001). Phytosterols and phytostanols: Functional food cholesterol busters. Food technology, 55: (1), 63-67.

Hussein, S.; El senosi, Y.;Hassanien, M. and Hammad, M.(2016). Evaluation of the protective role of flaxseed oil on inflammatory mediators, antioxidant defense system and oxidative stress of liver tissue in hypercholesterolemic rats. International Journal of pharma Sciences, 6:(3), 1480-89.

Ide, T.; Kobayashi, H.; Ashakumary, L.; Rouyer, I.; Takahashi, Y.; Aoyama, T., et al. (2000). Comparative effects of perilla and fish oils on the activity and gene expression of fatty acid oxidation enzymes in rat liver. Biochimica et Biophysica Acta (BBA) - Molecular and Cell Biology of Lipids, 1485: (1), 23-35.

Jain, A.; Aggarwal, K. and Zhang, P. (2015). Omega-3 fatty acids and cardiovascular disease. Eur Rev Med Pharmacol Sci, 19: (3), 441-5.

Karthick, M. and Prince, P. (2006). Preventive effect of rutin, a bioflavonoid, on lipid peroxides and antioxidants in isoproterenol-induced myocardial infarction in rats. Journal of Pharmacy and Pharmacology, 58: (5), 701-707.

Mair, J.; Wagner, I.; Jakob, G.; Lechleitner, P.; Dienstl, F.; Puschendorf, B., et al. (1994). Different time courses of cardiac contractile pro- 
teins after acute myocardial infarction. Clinica Chimica Acta, 231: (1), 47-60.

Mandimika, T.; Paturi, G.; De Guzman, C.; Butts, C.; Nones, K.; Monro, J., et al. (2012). Effects of dietary broccoli fibre and corn oil on serum lipids, faecal bile acid excretion and hepatic gene expression in rats. Food Chemistry, 131: (4), $1272-1278$.

Mantzioris, E.; James, M.; Gibson, R. and Cleland, L. (1994). Dietary substitution with an alpha-linolenic acid-rich vegetable oil increases eicosapentaenoic acid concentrations in tissues. The American journal of clinical nutrition, 59: (6), 1304-1309.

Milin, C.; Domitrovic, R.; Tota, M.; Giacometti, J.; Cuk, M.; Radosevic-Stasic, B., et al. (2001). Effect of olive oil-and corn oil-enriched diets on the tissue mineral content in mice. Biological trace element research, 82: (1-3), 201-210.

Mozaffarian, D. and Wu, J. (2011). Omega-3 fatty acids and cardiovascular disease. Journal of the American College of Cardiology, 58: (20), 2047-2067.

Murase, T.; Aoki, M. and Tokimitsu, I. (2005). Supplementation with ?-linolenic acid-rich diacylglycerol suppresses fatty liver formation accompanied by an up-regulation of ?-oxidation in zucker fatty rats. Biochimica et Biophysica Acta (BBA) - Molecular and Cell Biology of Lipids, 1733: (2-3), 224-231.

Mutiso, S.; Rono, D. and Bukachi, F. (2014). Relationship between anthropometric measures and early electrocardiographic changes in obese rats. BMC Research Notes, 7: (1), 931.

Nykter, M.; Kymalainen, H.; Gates, F. and Sjoberg, A. (2006). Quality characteristics of edible linseed oil. Agricultural and Food Science, 15: (4), 402-413.

Phan, D.; Silka, M.; Lan, Y. and Chang, R. (2015). Comparison of formulas for calculation of the corrected QT interval in infants and young children. The Journal of pediatrics, 166: (4), 960964.

Prasad, K. (2000). Flaxseed: A source of hypo- cholesterolemic and antiatherogenic agents. Drug News \& Perspectives, 13: (2), 99.

Prasad, K. (2005). Hypocholesterolemic and antiatherosclerotic effect of flax lignan complex isolated from flaxseed. Atherosclerosis, 179: (2), 269-275.

Prasad, K.; Mantha, S.; Muir, A. and Westcott, N. (2000). Protective effect of secoisolariciresinol diglucoside against streptozotocin-induced diabetes and its mechanism. Molecular and Cellular Biochemistry, 206: (1/2), 141-150.

Punithavathi, V. and Stanely Mainzen Prince, P. (2011). The cardioprotective effects of a combination of quercetin and ?-tocopherol on isoproterenol-induced myocardial infarcted rats. Journal of Biochemical and Molecular Toxicology, 25: (1), 28-40.

Rasmy, G. (2007). Protective effect of linseed oil on hyperlipidemia in experimental animals. $J$ Genet Eng Biotechnol, 5: 9-17.

Riaz, A.; Khan, R. and Ahmed, S. (2009). Assessment of anticoagulant effect of evening primrose oil. Pak J Pharm Sci, 22: (4), 355-9.

Rideout, T.; Harding, S.; Jones, P. and Fan, M. (2008). Guar gum and similar soluble fibers in the regulation of cholesterol metabolism: Current understandings and future research priorities. Vasc Health Risk Manag, 4: (5), 10231033.

Sammour, R. (1999). Proteins of linseed (linum usitatissimum L.), extraction and characterization by electrophoresis. Botanical Bulletin of Academia Sinica, 40.

Schirmer, M. and Phinney, S. (2007). ?-linolenate reduces weight regain in formerly obese humans. The Journal of nutrition, 137: (6), 14301435.

Si, H.; Zhang, L.; Liu, S.; LeRoith, T. and Virgous, C. (2014). High corn oil dietary intake improves health and longevity of aging mice. Experimental Gerontology, 58: 244-249.

Simopoulos, A. (2000). Human requirement for $n-$ 3 polyunsaturated fatty acids. Poultry Science, 79: (7), 961-970. 
Stoffel, W.; Holz, B.; Jenke, B.; Binczek, E.; Gunter, R. H.; Kiss, C., et al. (2008). ?6-desaturase (FADS2) deficiency unveils the role of ?3- and ?6-polyunsaturated fatty acids. EMBO J, 27: (17), 2281-2292.

Sun, S.; Wu, X.; Song, H. and Li, G. (2015). Baicalin ameliorates isoproterenol-induced acute myocardial infarction through INOS, inflammation, oxidative stress and P38MAPK pathway in rat. International journal of clinical and experimental medicine, 8: (12), 22063.

Tanaka, N.; Zhang, X.; Sugiyama, E.; Kono, H.; Horiuchi, A.; Nakajima, T., et al. (2010). Eicosapentaenoic acid improves hepatic steatosis
Atorvastatin and metformin in MetS Nehal $\mathrm{H}$ et al. 62 independent of PPAR? activation through inhibition of SREBP-1 maturation in mice. Biochemical Pharmacology, 80: (10), 1601-1612.

Tzang, B.; Yang, S.; Fu, S.; Yang, H.; Sun, H. and Chen, Y. (2009). Effects of dietary flaxseed oil on cholesterol metabolism of hamsters. Food Chemistry, 114: (4), 1450-1455.

Yokoyama, M. (2004). Oxidant stress and atherosclerosis. Current Opinion in Pharmacology, 4: (2), 110-115.

Zanwar, A.; Hegde, M. and Bodhankar, S. (2010). In vitro antioxidant activity of ethanolic extract of linum usitatissimum. Pharmacology online, 1: 683-696. 